\title{
Correction to: 3D Bioprinting Technologies
}

\author{
Christopher B. Highley
}

\section{Correction to:}

Chapter 1 in: M. Guvendiren (ed.), 3D Bioprinting in Medicine, https://doi.org/10.1007/978-3-030-23906-0_1

This book was inadvertently published without updating the corrections to chapter 1. The same has been updated in all renditions of the book. 